\title{
ESTUDO DO USO DO TAMARINDO COMO ADJUNTO DO MALTE PARA PRODUÇÃO DE CERVEJAS ALE E LAGER
}

\author{
R.M.F. da SILVA ${ }^{1}$, T.S. CHALEGRE ${ }^{1}$ e G.B.M. de CARVALHO ${ }^{1}$ \\ ${ }^{1}$ Universidade Estadual de Feira de Santana, Departamento de Tecnologia \\ E-mail para contato: gbmafra@yahoo.com.br
}

\begin{abstract}
RESUMO - Cerveja é uma bebida resultante da fermentação pelas leveduras do mosto feito com malte de cevada e lúpulo. Podem ser acrescentados adjuntos, que são outras fontes de carboidratos fermentescíveis, com o objetivo de baratear a produção e conferir diferente sabor e aroma à bebida. Esse trabalho objetivou testar o tamarindo como adjunto do malte, por ser um fruto abundante no Nordeste, com potencial de uso ainda pouco explorado. Foram feitas fermentações de mosto cervejeiro com suco de tamarindo nas concentrações de 10 e 30\%, utilizando leveduras ale e lager. Para produção de uma cerveja Ale, a melhor concentração de adjunto obtida foi de $10 \%$, com Yp/s máximo de $0,41 \mathrm{~g} / \mathrm{g}$ e Qp máximo de 1,05g/L.h. Para produção de uma cerveja Lager, a concentração de $30 \%$ de adjunto foi a mais favorável para a fermentação, com Yp/s máximo de 0,39 g/g e Qp máximo de $0,65 \mathrm{~g} / \mathrm{L}$.h. Os bons parâmetros fermentativos obtidos mostram que o tamarindo tem potencial de uso como adjunto na produção de cerveja.
\end{abstract}

\section{INTRODUÇÃO}

A legislação brasileira define a cerveja como bebida obtida pela fermentação alcoólica do mosto cervejeiro oriundo do malte de cevada e água potável, por ação da levedura, com adição de lúpulo. Parte do malte da cevada pode ser substituída por adjuntos (Brasil, 1997), que são outras fontes de carboidratos fermentáveis que deixam a bebida mais leve e reduzem o custo de produção, a exemplo do milho e do arroz (Oliveira, 2013).

As cervejas são classificadas em dois grandes estilos, ale e lager. A cerveja lager é produzida por leveduras de baixa fermentação, que floculam ao final da fermentação primaria, sendo coletadas na base do fermentador. Devido às baixas temperaturas, que variam entre $7 \mathrm{e}$ $15^{\circ} \mathrm{C}$, a fermentação pode levar de 7 a 10 dias. A produção da cerveja Ale ocorre com fermentação em temperaturas entre 18 e $22^{\circ} \mathrm{C}$, durante um período de 3 a 5 dias. Ao final do processo fermentativo, as leveduras adsorvidas nas bolhas de $\mathrm{CO}_{2}$ ficam na superfície do mosto, onde podem ser coletadas. A diferença entre leveduras ale e lager, baseada na sua presença no fundo ou na superfície do mosto, tem sido menos utilizada a partir do maior uso dos fermentadores cilindro-cônicos e das centrífugas (Araujo et al, 2003; Oetterer et al., 2006). . 
A cerveja é considerada uma bebida de sabor e aroma complexos, pois é necessário que haja um equilíbrio entre as concentrações dos seus compostos para que a qualidade seja assegurada. Entre os compostos mais importantes, estão os ésteres, aldeídos, alcoóis superiores e fenóis. A ocorrência de sabores indesejáveis afeta negativamente a qualidade da bebida sendo um grande problema nas indústrias cervejeiras (Araujo et al, 2003).

Com o mercado cada vez mais competitivo e consumidores mais exigentes, as indústrias buscam elaborar produtos de boa qualidade com custos reduzidos. Para diminuir os custos na fabricação da cerveja, o setor cervejeiro utiliza adjuntos, que são mais baratos em comparação ao malte (Hough, 1991). Muitos estudos estão sendo realizados com o intuito de criar novas formulações para a bebida utilizando-se adjuntos cervejeiros alternativos. Enquanto as grandes cervejarias utilizam normalmente milho e arroz, alguns adjuntos incomuns, como frutas e mel, têm sido testados para produção de cerveja em microcervejarias, onde o propósito é utilizá-los para melhorar e inovar o aroma e sabor da bebida (Oliveira, 2013).

O Brasil é um dos maiores produtores mundiais de frutas. Porém, há uma grande perda póscolheita para algumas culturas, gerando prejuízos ao agricultor. Assim, é importante que haja alternativas para evitar desperdícios e também aumentar a renda do agricultor. Uma das possibilidades é a produção de bebidas alcoólicas a partir de frutas cultivadas em solo brasileiro (Dias et al., 2003). O fruto tamarindo (Tamarindus indica L.) é uma opção de adjunto que pode ser utilizado na produção de cerveja, substituindo parcialmente o malte. No Brasil, o fruto é encontrado principalmente nos estados do Nordeste. Com sabor agridoce, a polpa freqüentemente é consumida fresca, mas também apresenta outros usos culinários, podendo ser utilizada no preparo de doces, bolos, sorvetes, xaropes, bebidas, licores, refrescos, sucos e ainda como tempero para arroz, carne, peixe e outros alimentos (Santos-Serejo, 2009).

Experimentos visando a otimização do processo fermentativo cervejeiro, através da utilização de novos adjuntos, são hoje um dos principais caminhos da indústria cervejeira na redução dos custos operacionais e consequentemente no ganho da competitividade no mercado. Neste sentido, este trabalho visa agregar valor ao tamarindo, matéria prima amplamente encontrada na região Nordeste, com o desenvolvimento de um processo cervejeiro que seja mais viável economicamente.

\section{METODOLOGIA}

\subsection{Preparo do mosto}

O mosto cervejeiro foi preparado de acordo com a Figura 1, através das principais etapas do processo. $\mathrm{O}$ mosto foi ajustado para $12^{\circ}$ Brix e $\mathrm{pH} 5,2$. 


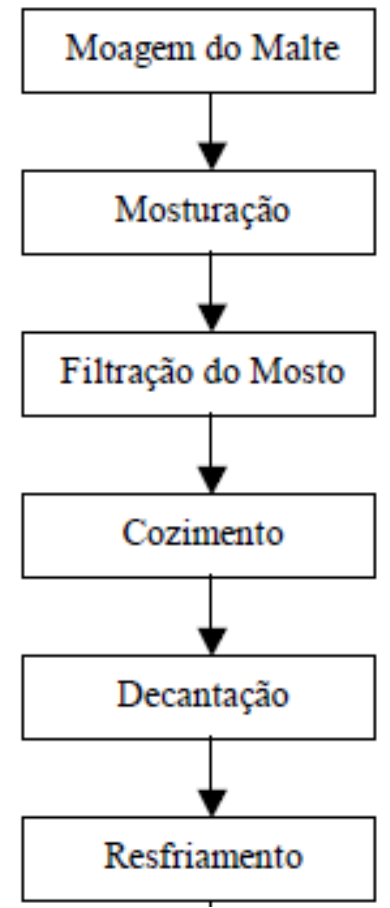

Figura 1- Fluxograma do processo de produção do mosto cervejeiro (adaptado de Kalnin, 1999).

\subsection{Chaptalização do suco de tamarindo}

O suco foi preparado com polpas comerciais de tamarindo da marca Brasfrut ${ }^{\circledR}$, adquiridas na cidade de Feira de Santana, Bahia, as quais foram adicionadas água na proporção 1:1. A chaptalização (ajuste do Brix) foi feita com a adição de sacarose comercial até o valor de $12^{\circ}$ Brix, característico de mostos convencionais. Cada $25 \mathrm{~g}$ de sacarose adicionados a um volume final de $1 \mathrm{~L}$ eleva o ${ }^{\circ}$ Brix do mosto em, aproximadamente, 2 unidades (Dias et al., 2003).

\subsection{Ajuste do pH}

$\mathrm{O}$ pH do suco foi ajustado até o valor de 5,2, com a adição de carbonato de cálcio $\left(\mathrm{CaCO}_{3}\right)$. Após essa etapa, adicionou-se metabissulfito de potássio para evitar contaminação microbiana.

\subsection{Fermentação do mosto com adjunto}

Ao mosto previamente preparado foi adicionado suco de tamarindo nas concentrações de 10 e $30 \%$, totalizando um volume final de $125 \mathrm{~mL}$. As fermentações foram conduzidas em triplicata em Erlenmeyers de $250 \mathrm{~mL}$. Utilizou-se, separadamente, dois tipos de leveduras comerciais liofilizadas: Saccharomyces cerevisiae do tipo lager e do tipo ale, nas quantidades indicadas no rótulo, 


\section{9 a 22 de outubro de 2014 \\ Florianópolis/SC}

equivalentes a $1 \times 10^{7} \mathrm{cel} / \mathrm{mL}$. Os ensaios foram realizados em estufa BOD na temperatura de $15^{\circ} \mathrm{C}$ para a levedura lager e $22^{\circ} \mathrm{C}$ para a levedura ale. A cada $12 \mathrm{~h}$ eram retiradas duas amostras de $1 \mathrm{~mL}$ de cada ensaio para que fosse feito o acompanhamento analítico da fermentação. Com uma das amostras foi realizada a contagem de células viáveis e não-viáveis em câmara de Neubauer (1/400 mm2 x 1/10 $\mathrm{mm}$ ). A outra amostra foi centrifugada, em centrífuga de Eppendorf (13000 rpm por 10 minutos), e o sobrenadante foi usado para a realização de análises no densímetro de bancada da marca Rudolph Research Analytical, modelo DDM 2911, no qual foram analisados o teor de etanol (\%v/v), densidade $(\mathrm{g} / \mathrm{mL})$, extrato aparente $\left({ }^{\circ}\right.$ Plato) e sólidos solúveis $\left({ }^{\circ}\right.$ Brix). O tempo total da fermentação foi de 156 horas, para os mostos fermentados com levedura lager, e 96horas, para aqueles fermentados com levedura ale. Esses períodos de tempo foram definidos a partir da estabilidade dos valores de densidade

\section{RESULTADOS E DISCUSSÃO}

\subsection{Concentração celular e redução da densidade}

Durante o processo fermentativo, normalmente podem ser observadas diferentes fases do crescimento microbiano: inicialmente, há uma fase de latência, em que as células se adaptam ao meio após serem inoculadas e não crescem de forma significativa. Em seguida, há a fase de crescimento exponencial, com o consumo intenso de nutrientes e oxigênio e produção de metabólitos. O crescimento começa a estacionar e, por fim, há a fase de declínio, na qual o número de células diminui, devido à escassez de nutrientes e maior concentração de produtos tóxicos (Madigan et al., 2004). Durante a fermentação pela levedura lager, o número máximo de células observado quando se utilizou $10 \%$ de adjunto foi $1 \times 10^{8} \mathrm{cel} / \mathrm{ml} \mathrm{com} 84 \mathrm{~h}$ de fermentação e, no mosto com $30 \%$ de suco de tamarindo, $8,4 \times 10^{7} \mathrm{cel} / \mathrm{ml}$ com $144 \mathrm{~h}$ de fermentação, conforme mostrado na Figura 2. Esse último resultado pode ser considerado incomum, visto que o maior número de células foi contabilizado ao final do processo fermentativo, quando o esperado é que nesse tempo o número de células seja menor. Porém, um número alto de células em suspensão não significa que todas estejam viáveis, ou seja, capazes de metabolizar os açúcares.

Os mostos fermentados pela levedura ale apresentaram número máximo de células em suspensão com 24h de fermentação, porém o valor máximo alcançado para o mosto com $30 \%$ de suco de tamarindo foi superior ao mosto com 10\% do adjunto. Enquanto a amostra com menos adjunto apresentou $7,7 \times 10^{7} \mathrm{cel} / \mathrm{ml}$ no ponto máximo, a amostra com $30 \%$ de tamarindo apresentou $8,7 \times 10^{7} \mathrm{cel} / \mathrm{ml}$. Observou-se que, em ambos os casos, a fase de declínio começou após $24 \mathrm{~h}$ e, a partir desse ponto, o número de células sofreu algumas oscilações, o que pode ser explicado pela floculação, mecanismo natural de agregação de leveduras que ocorre na fermentação alcoólica principalmente ao final da fermentação (Gibson et al., 2007). A obtenção da máxima concentração de leveduras em suspensão em menor tempo na fermentação conduzida pela levedura Ale pode ser explicada pela maior temperatura requerida por esse tipo de levedura no processo fermentativo e, consequentemente, pelo seu metabolismo mais rápido (Morado, 2009). 


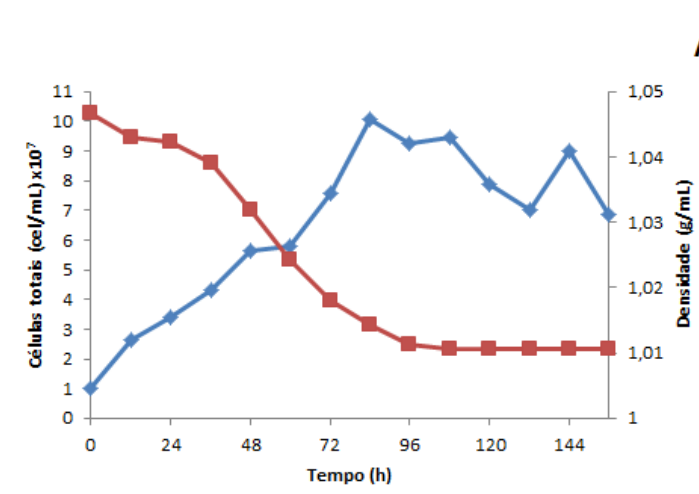

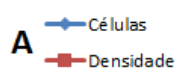
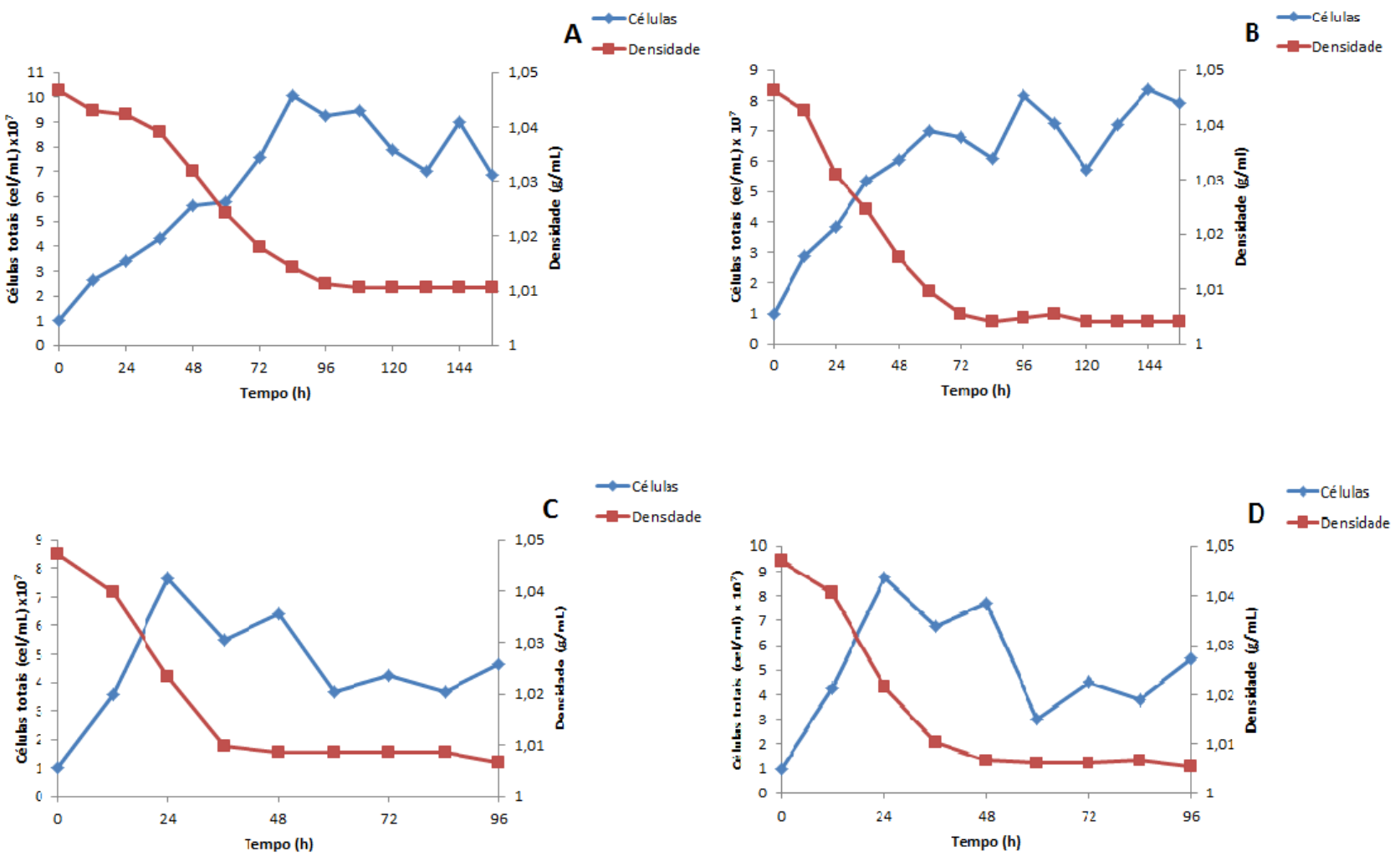

Figura 2 - Variação da concentração celular e densidade durante o processo fermentativo. (A) e (B) Fermentação usando levedura lager nas concentrações de 10 e 30\% de adjunto, respectivamente. (C) e (D) Fermentação com levedura ale nas concentrações de 10 e $30 \%$ de adjunto, respectivamente.

$\mathrm{Na}$ fermentação, a densidade do mosto é influenciada pelos principais produtos que são formados, etanol e $\mathrm{CO}_{2}$. A densidade do etanol é 0,789 $\mathrm{g} / \mathrm{L}$ (Silva et al., 2008) e com a sua produção crescente ao longo da fermentação, a densidade do mosto tende a diminuir. Portanto, o metabolismo das leveduras e sua conversão dos açúcares em etanol tem influência direta sobre a densidade do mosto, o que é possível observar nos gráficos, que mostram que a densidade diminuiu de forma progressiva no início da fermentação e se estabilizou quando as leveduras entraram em fase de declínio. Comparando-se as amostras fermentadas com levedura lager, a amostra com maior concentração de adjunto teve maior redução na densidade, $4,1 \%$, enquanto a amostra com menos adjunto apresentou 3,5\% de redução. Com relação às amostras fermentadas com levedura ale, houve maior redução na amostra com mais suco de tamarindo, 3,98\%, contra $3,87 \%$ da amostra com menos tamarindo.

\subsection{Produção de etanol}




\section{9 a 22 de outubro de 2014 \\ Florianópolis/SC}

Observou-se que nas fermentações utilizando a levedura lager, o mosto com 30\% de adjunto apresentou maior teor final de etanol $(42,84 \mathrm{~g} / \mathrm{L}$ ou $5,43 \%)$ do que o mosto preparado com $10 \%$ de suco de tamarindo (36,76 g/L ou 4,66\%). As amostras 3 e 4, fermentadas com levedura ale, também apresentaram diferenças na concentração final de etanol. Porém, pelo teste de Tukey, cujos resultados encontram-se na tabela 1, tais diferenças na concentração final de etanol não possuem diferenças significativas entre si. O mosto com $10 \%$ de adjunto apresentou $43,39 \mathrm{~g} / \mathrm{L}$ (5,21\%), enquanto o mosto com $30 \%$ de suco de tamarindo apresentou 41,81 g/L $(5,37 \%)$. A maior concentração de adjunto no mosto também favoreceu o consumo de extrato. Quando utilizou-se a levedura lager, houve consumo de 78,1\% de extrato quando a concentração de adjunto foi $10 \%$, contra redução de $91,45 \%$ de extrato quando foi utilizado $30 \%$ de suco de tamarindo. Nas fermentações com levedura ale, houve redução de $86,38 \%$ com uso de $10 \%$ de adjunto, e 88,92\% quando $30 \%$ de adjunto foi adicionado.

Tabela 1- Teste de Tukey para a média dos valores de etanol $(\mathrm{g} / \mathrm{L})$ e extrato aparente $(\mathrm{g} / \mathrm{L})$ no tempo final da fermentação das amostras com 10 e 30\% de adjunto. Médias seguidas de mesma letra minúscula e mesmo número na linha não diferem entre si em nível de $5 \%$ de significância

\begin{tabular}{lll}
\hline Tipo de levedura & Parâmetro (g/L) & Média \\
\hline Ale & Etanol (10\% de adjunto) & $43.39000 \mathrm{a} 1$ \\
& Etanol (30\% de adjunto) & $41.81000 \mathrm{a} 1$ \\
& Extrato (10\% de adjunto) & $16.81000 \mathrm{a} 2$ \\
Lager & Extrato (10\% de adjunto) & $13.67000 \mathrm{~b} 2$ \\
& Etanol (10\% de adjunto) & $36.76000 \mathrm{a} 3$ \\
& Etanol (30\% de adjunto) & $42.84000 \mathrm{~b} 3$ \\
& Extrato (10\% de adjunto) & $26.78000 \mathrm{a} 4$ \\
& Extrato (10\% de adjunto) & $10.36000 \mathrm{~b} 4$ \\
\hline
\end{tabular}

\subsection{Produtividade volumétrica em etanol $(Q p)$ e rendimento real em etanol $(\mathbf{Y p} / \mathbf{s})$}

Foram calculados dois parâmetros fermentativos: produtividade volumétrica em etanol (Qp), que é a relação entre a quantidade de etanol produzida e o tempo de fermentação, e o rendimento real em etanol (Yp/s), que é a relação entre a quantidade de etanol produzida e o extrato consumido. A concentração de $30 \%$ foi a que mais favoreceu a fermentação com levedura lager, pois o Yp/s foi de 0,39 g/g no tempo de 60h e o Qp foi de 0,65 g/L.h no tempo de 48h, valores maiores que os encontrados na fermentação com $10 \%$ de adjunto (tabela 1). Nas fermentações com levedura ale, observou-se que o Yp/s foi mais elevado quando o suco de tamarindo foi usado na concentração de $10 \%$ (0,41 g/g em $96 \mathrm{~h}$ de fermentação), porém o Qp foi mais alto na concentração de $30 \%$ (1,08g/L.h no tempo de $24 \mathrm{~h})$.

\section{CONCLUSÃO}

Considerando-se os resultados das fermentações realizadas, conclui-se que o tamarindo tem 
um bom potencial para ser utilizado como adjunto do malte na produção de cerveja. A melhor concentração a ser utilizada depende do tipo de cerveja que se quer produzir. A concentração de $30 \%$ de suco de tamarindo demonstrou ser a melhor na produção de uma cerveja lager, enquanto $10 \%$ é a concentração mais favorável na produção de uma cerveja ale.

\section{REFERÊNCIAS}

ARAÚJO, F. B.; SILVA, P. H. A.; MINIM, V. P. R. Perfil sensorial e composição físico-química de cervejas provenientes de dois segmentos do mercado brasileiro. Ciênc. Tecnol. Aliment., v. 23, n. 2, p. 121-128, 2003

BRASIL, Decreto no 2.314 de 4 de setembro de 1997. Diário Oficial (República Federativa do Brasil). p.19549. 1997

DIAS, D. R.; SCHWAN, R. F.; LIMA, L. C. O. Metodologia para elaboração de fermentado de cajá (Spondias mombin L.). Ciênc. Tecnol. Aliment., v. 23, n. 3, 2003.

DRAGONE, G., SILVA, D.P., Factors influencing ethanol production rates at high-gravity brewing. Lebensm.-Wiss. u.-Technol.,v.37, p.797-802, 2004.

GIBSON, B.R.; LAWRENCE, S.J.; LECLAIRE, J.P.R.; POWELL, C.D.; SMART, K.A. Yeast responses to stresses associatedwith industrial brewery handling. FEMS Microbiol Rev., vol 31, p. 535-569, 2007.

HOUGH, J. S. The biotechnology of malting and brewing. Cambridge, Cambridge University Press, 1991.

KALNIN, J.L. Avaliação estratégica para implantação de pequenas cervejarias. Dissertação. Florianópolis, UFSC,1999.

MADIGAN, M. T.; MARTINKO, J. M.; PARKER, J. Microbiologia de Brock. 10.ed. São Paulo: Prentice-Hall do Brasil, 2004.

MARTINS, C.A.P. Avaliação do efeito do inóculo e do perfil de alimentação do mosto na produção em escala piloto e industrial de etanol. Dissertação. São Carlos, São Paulo, Brasil. Abril de 2009. Programa de pós graduação em Engenharia química da Universidade Federal de São Carlos.

MORADO, R. Larousse da Cerveja. São Paulo, Larousse do Brasil, 2009.

OETTERER, M.; REGITANO-D'ARCE, M. A. B.; SPOTO, M. H. F. Fundamentos de ciência e tecnologia de alimentos. Barueri, SP, Manole, 2006 
OLIVEIRA, M. Cerveja brilhante. Pesquisa FAPESP. V.204, p. 50-55, 2013.

SANTOS-SEREJO, J. A. Fruticultura Tropical: especies regionais e exoticas. Brasília, Embrapa Informação Tecnologica, 2009.

SILVA, J.A.; DAMASCENO, B.P.G.L.; SILVA, F.L.H.; MADRUGA, M.S.; SANTANA, D.P. Aplicação da metodologia de planejamento fatorial e análise de superfícies de resposta para otimização da fermentação alcoólica. Quím. Nova, v.31, n.5, 2008.

SOUZA, M. A. C.; MUTTON, M. J. R. Floculação de leveduras por Lactobacillus fermentum em processos industriais de fermentação alcoólica avaliada por técnica fotométrica. Ciênc. Agrotec., v. 28, n. 4, 2004. 